\title{
NHS Lothian HSDU Project
}

1 OVERVIEW OF THE OBSERVATION TECHNIQUE .............................................

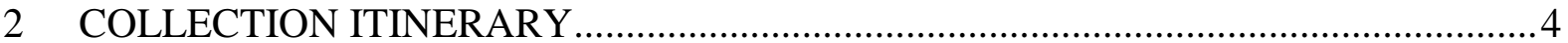

2.1 Domain Analysis criteria.................................................................................

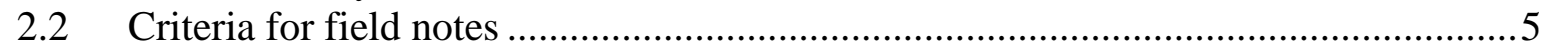

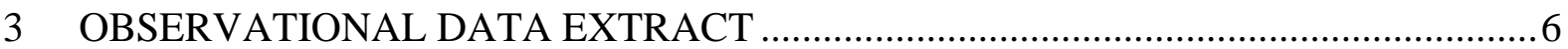

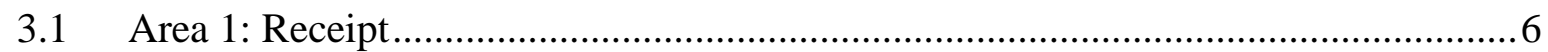

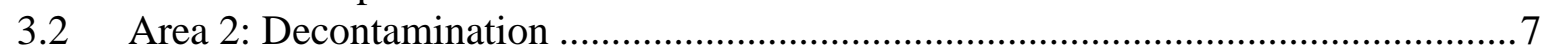

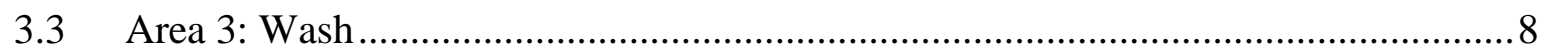

3.4 Area 4: Assembly ..................................................................................

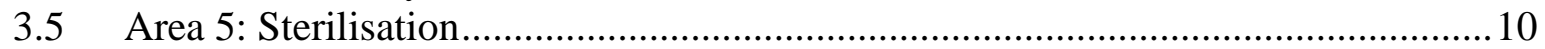

3.6 Area 6: Despatch .....................................................................................

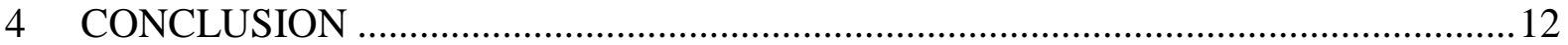

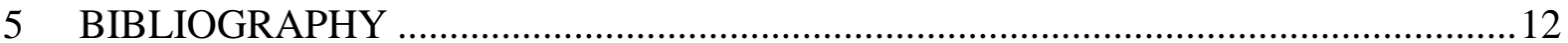

6 APENDIX 1: OBSERVATION AND DIARY SHEET EXAMPLES ………………......13 


\section{OVERVIEW OF THE OBSERVATION TECHNIQUE}

The aim of these observations conducted was to collect data which could allow the understanding of how people think and how they react to issues within the HSDU. Over the observation period there was a total of 40 diary pages collected and 8 unscheduled interviews conducted. The start date for the observations was July $10^{\text {th }}$, continuing to august $23^{\text {rd }}$ which allowed 30 Observation hours and 24 observations. data collection followed the itinerary described in section 4 .

The following text explains the methodology behind the observations conducted.

Denscombe (2007) describes participant observation as a relevant starting point for research surrounding the HSDU project because a task related to a specific process is an important facet to consider when dealing personal experiences and interpretations. This view is embedded within the methodology of ethnography and it is this approach to participant observation which primarily informs this study. A secondary view by Llewellyn (1993) supports this position by advising that the interpretive task in a study such as this, surrounds the explication of subjective understandings. In this respect, adopting this dual consideration, observations of this type can draw together assumptions about how people know what they know and which are embodied within. Similarly, Laughlin (1995) advises that an individual observer is permitted and encouraged to be free to be involved in the observation process, completely uncluttered by theoretical rules and regulations on what is to be seen and how the seeing should be undertaken (Laughlin 1995, p 67). Because of the distinct and complex nature of the study, and in contrast to some conventional approaches Laughlin informs this study regarding ethnographic research, because ethnographic research from his perspective allows a low level of prior ontological theorising. This initial perspective was important for this data collection because there is little in the way of empirical studies for the phenomena under investigation. In addition to this, and importantly for this research, Wilkinson and Birmingham (2003) proposed an argument in which participant observation has the potential to come closer to a naturalistic emphasis, because the qualitative researcher confronts members of a social setting in their natural environments. This approach allowed for observations which indicated understanding of relevant knowledge and values from personal perspectives. This unique approach allowed the study to draw together qualitative integration of philosophical principles. 
Observational interpretation was therefore important for this research since the topic of perspective form the HSDU staff needed to be explored, not measured, since any participant interactions such as experience, which could not be accurately measured, must be interpreted.

Consciousness: $\quad H S D U$ practitioners are aware of themselves as unique individuals and their relationship to others

Action: HSDU practitioners make deliberate choices regarding certain behaviour in certain situations.

Unpredictability: If human behaviour in any context is of an unpredictable nature, then corresponding modes of study are required to interpret this unpredictability.

Observation Interpretation (Self)

From a practical consideration, this is formally acknowledged by Wilkinson and Birmingham (2003) who concluded that the criteria for using participant observation is,

When the ways in which people behave and interact with each other in a social setting are important to the research. $\sqrt{ }$

When researching a social settings and what happens in them is of interest. $\sqrt{ }$ When the best way to research the unknown is to experience it for oneself. $\sqrt{ }$ When the context of the events being researched is important. $\sqrt{ }$ As a useful supplement to other research instruments. $\sqrt{ }$ When a flexible approach is needed. $\sqrt{ }$

Source: Wilkinson and Birmingham (2003, p118)

Participant observation was carried out as part of ethnographic research and was accompanied by some ad Hoch interviews at the time of observation. Observational data collection was transcribed through an interpretivist lens, which was important for this study because interpretivism, related to the qualitative position of the research, utilises analysis around the basic principles at the core of this research, THE FIGURATIONAL APPROACH. Figurational sociology (process sociology) Elias (1897-1990), is a dynamic web of human beings, the emphasis being placed on people in the plural and how people are tied into social networks because of their interdependence with each other (Elias, 1978). Within the HSDU the study focus involves all members of the HSDU department staff. In short, the whole network of interdependencies involved in the formulation and implementation of the process to clean and sterilise equipment. The concept of figuration overcomes some of the theoretical 
problems linked with traditional sociological terms and theories. In particular, misleading dichotomies such as those between the individual and society, or, 'agent' and 'structure'. In this respect, Elias (1978), noted that it is not productive to consider the 'individual' and 'society' as two separate entities, instead, that these two concepts refer to 'inseparable levels of the same human world' (Murphy et al, 2000, p. 92). In the context of this study, HSDU process agents are affected by the actions of other process agents, who are bounded together by management structures, overarched by expectant outcomes (interaction, meaning, justification Interpretation) etc etc.

\section{COLLECTION ITINERARY}

All observations were conducted within the following criteria: Continuously observe what happens during the working day to a maximum of 4 people who work in the same location over a period of approximately 1-3 hours at 30-minute intervals. For each observation, record staff state of being, engagement, and interaction with people in close proximity and followed the broad caveat of domain analysis.

\subsection{Domain Analysis criteria}

- Social Setting: includes the various attributes of the scene which is being observed or studied. For, example size, physical features, the internal organization, and the location of the room in which that observed takes place.

- Physical Environment.

- Space and the Objects in the Setting.

- Actors in the Setting.

- Events. Planned activity

- Time.

- Individual Behaviour: behavioural acts which are taking place at the event. characteristics of behaviour that might have meaning.

- Activities. behavioural acts that seem to be related.

- Actor Groups. actors in the setting related, linked or differentiated

- Interactive Patterns of dominant and subordinate personality, compatible behaviours or opposing behaviours between one or more set of actors and actors who facilitate or instigate a particular type of behaviour between the set of actors?

- Language. Pleasant, formal, informal, unpleasant

- Non-Verbal Behaviour and Metalingual Properties in Conversation. gestures or other forms of nonverbal behaviour that might have some relevance to interactions in the setting.

- Expressive Culture. expressive culture found in the social setting beyond general language

- Ideational Elements. any of the other domains (behaviours, characteristics of actors, space, objects, interactive patterns, expressive culture, etc.) which reflect beliefs, attitudes, values, or any other cognitive constructs that might suggest various socio-cultural meanings which may be present in or attached to any of the other ethnographic domains in the setting

- Goals, Motivations, or Agendas.

- Broader Social Systems. 
This overarching criteria was drawn into a more manageable/practical sub set, supported by a strict criteria for field note writing.

- $\quad\{P S\}$ Physical setting.

- $\quad\{$ A\}Activities.

- $\quad$ PA\}Patterns of interactions, frequency of interactions, direction of communication patterns, decisionmaking patterns.

- $\quad$ FI\}Formal interactions.

- $\quad\{$ II\}Informal interactions and unplanned activities.

- $\{$ NC\}Nonverbal communication.

- $\quad\{N H\} O b s e r v i n g$ what does not happen.

\subsection{Criteria for field notes}

- Accurate as possible

- Detailed, but not cluttered with irrelevant trivia.

- Extensive enough to permit the reader to understand the situation described.

- Provide an overview of a culture or setting. More than simply record a setting so include insights and thoughts about what was observed. These comments though will be included in a separate, reflective part of the field notes and are not in the descriptive part of the notes.

Key points of observation regarding understanding, communicative experiences were highlighted in observation sheets (See appendix 1), these were then transcribed. Completed data sheets for individual observations were then given correlation numbers to indicate location, date, time and number of participants, which will allow for cross referencing. I introduced this additional criteria to allow for the maximum amount of data to be collected in the limited amount of time I was allowed access to the unit. 


\section{OBSERVATIONAL DATA EXTRACT}

\subsection{Area 1: Receipt}

\begin{tabular}{|c|c|c|c|c|}
\hline Observational Area 1 & Method & Participants & $\begin{array}{l}\text { Observatio } \\
n s\end{array}$ & Format \\
\hline $\begin{array}{r}4 \text { hours Fieldwork Timetable: } 2 \text { days } \\
\text { @ 2hrs per day }\end{array}$ & $\begin{array}{l}\text { Participant } \\
\text { Observations }\end{array}$ & 2 & 4 & Field Notes \\
\hline
\end{tabular}

$\{P S\}$

Located at the rear of a very busy hospital on the outskirts of Edinburgh. Difficult to locate, is not signposted within the main hospital entrance. Looked like an industrial unit from the outside. Difficult to identify the main entrance as this was located to the very rear of the building. Natural instinct would expect to see it at the front of the building.

Several medium sized trucks were parked outside and large containers which looked like meals on wheels trolleys were being unloaded onto the courtyard.

This was a daily occurrence as the unit is opened 24 hrs a day. This looked like a two man job, but was carried out by a single person. Once inside the unit, the trolley was identified and opened to identify the contents. No operational instructions were uttered, which gave the appearance of complete knowledge of the process.

The 2 staff who were in this area knew exactly what to do with the items inside and were clearly very confident in their approach to the nature of the contents. Since these were surgical instruments and items used to operate on people and were inevitably covered in blood and tissue. Their attitude to the contents was very matter of fact. The relationship between them was quite light almost light hearted

One item slipped as it was being examined inside the trolley but did not seem to phase either person.

When unloading and scanning items from the trolley, the conversations were of a social nature and there was no direct instructions passed between the participants during the unloading process.

The lack of communication regarding the actual work being undertaken seemed to be sparse, almost non existent. 


\begin{tabular}{|c|c|c|c|c|}
\hline Observational Area 2 & Method & Participants & $\begin{array}{l}\text { Observatio } \\
\text { ns }\end{array}$ & Format \\
\hline $\begin{array}{r}6 \text { Fieldwork Timetable: } 3 \text { days } \\
@ 2 \text { hrs per day }\end{array}$ & $\begin{array}{l}\text { Participant } \\
\text { Observations }\end{array}$ & 4 & 4 & Field Notes \\
\hline
\end{tabular}

$\{P S\}$

Located at the rear of a very busy hospital on the outskirts of Edinburgh. Difficult to locate, is not signposted within the main hospital entrance. Looked like an industrial unit from the outside. Difficult to identify the main entrance as this was located to the very rear of the building. Natural instinct would expect to see it at the front of the building.

$\{A\}$

Several medium sized trucks were parked outside and large containers which looked like meals on wheels trolleys were being unloaded onto the courtyard.

$\{P A\}$

This was a daily occurrence as the unit is opened $24 \mathrm{hrs}$ a day. This looked like a two man job, but was carried out by a single person. Once inside the unit, the trolley was identified and opened to identify the contents. No operational instructions were uttered, which gave the appearance of complete knowledge of the process.

The 2 staff who were in this area knew exactly what to do with the items inside and were clearly very confident in their approach to the nature of the contents. Since these were surgical instruments and items used to operate on people and were inevitably covered in blood and tissue. Their attitude to the contents was very matter of fact. The relationship between them was quite light almost light hearted

\section{$\{$ II $\}$}

One item slipped as it was being examined inside the trolley but did not seem to phase either person.

$\{N C\}$

When unloading and scanning the items from the trolley, the conversation was of a social nature and there was no direct instructions passed between the participants of the unloading process.

$\{N H\}$

The lack of communication regarding the actual work being undertaken seemed to be sparse, almost non existent. 


\subsection{Area 3: Wash}

\begin{tabular}{|c|c|c|c|c|}
\hline Observational Area 3 & Method & Participants & $\begin{array}{l}\text { Observatio } \\
\text { ns }\end{array}$ & Format \\
\hline $\begin{array}{r}4 \text { hours Fieldwork Timetable: } 2 \text { days } \\
\text { @ 2hrs per day }\end{array}$ & $\begin{array}{c}\text { Participant } \\
\text { Observations }\end{array}$ & 2 & 4 & Field Notes \\
\hline
\end{tabular}

\section{$\{P S\}$}

Located at the rear of a very busy hospital on the outskirts of Edinburgh. Difficult to locate, is not signposted within the main hospital entrance. Looked like an industrial unit from the outside. Difficult to identify the main entrance as this was located to the very rear of the building. Natural instinct would expect to see it at the front of the building.

\section{$\{A\}$}

Several medium sized trucks were parked outside and large containers which looked like meals on wheels trolleys were being unloaded onto the courtyard.

This was a daily occurrence as the unit is opened $24 \mathrm{hrs}$ a day. This looked like a two man job, but was carried out by a single person. Once inside the unit, the trolley was identified and opened to identify the contents. No operational instructions were uttered, which gave the appearance of complete knowledge of the process.

The 2 staff who were in this area knew exactly what to do with the items inside and were clearly very confident in their approach to the nature of the contents. Since these were surgical instruments and items used to operate on people and were inevitably covered in blood and tissue. Their attitude to the contents was very matter of fact. The relationship between them was quite light almost light hearted

$\{$ II $\}$

One item slipped as it was being examined inside the trolley but did not seem to phase either person.

When unloading and scanning the items from the trolley, the conversation was of a social nature and there was no direct instructions passed between the participants of the unloading process.

The lack of communication regarding the actual work being undertaken seemed to be sparse, almost non existent. 


\subsection{Area 4: Assembly}

\begin{tabular}{|c|c|c|c|c|}
\hline Observational Area 4 & Method & Participants & Observatio & Format \\
\hline $\begin{array}{r}6 \text { hours Fieldwork Timetable: } 3 \text { days } \\
@ 2 h r s p e r d a y\end{array}$ & $\begin{array}{c}\text { Participant } \\
\text { Observations }\end{array}$ & 4 & 6 & Field Notes \\
\hline
\end{tabular}

\section{$\{P S\}$}

Located at the rear of a very busy hospital on the outskirts of Edinburgh. Difficult to locate, is not signposted within the main hospital entrance. Looked like an industrial unit from the outside. Difficult to identify the main entrance as this was located to the very rear of the building. Natural instinct would expect to see it at the front of the building.

$\{A\}$

Several medium sized trucks were parked outside and large containers which looked like meals on wheels trolleys were being unloaded onto the courtyard.

This was a daily occurrence as the unit is opened $24 \mathrm{hrs}$ a day. This looked like a two man job, but was carried out by a single person. Once inside the unit, the trolley was identified and opened to identify the contents. No operational instructions were uttered, which gave the appearance of complete knowledge of the process.

The 2 staff who were in this area knew exactly what to do with the items inside and were clearly very confident in their approach to the nature of the contents. Since these were surgical instruments and items used to operate on people and were inevitably covered in blood and tissue. Their attitude to the contents was very matter of fact. The relationship between them was quite light almost light hearted

$\{$ II $\}$

One item slipped as it was being examined inside the trolley but did not seem to phase either person.

$\{N C\}$

When unloading and scanning the items from the trolley, the conversation was of a social nature and there was no direct instructions passed between the participants of the unloading process.

The lack of communication regarding the actual work being undertaken seemed to be sparse, almost non existent. 


\subsection{Area 5: Sterilisation}

\begin{tabular}{|c|c|c|c|c|}
\hline Observational Area 5 & Method & Participants & $\begin{array}{l}\text { Observatio } \\
n s\end{array}$ & Format \\
\hline $\begin{array}{r}6 \text { Hours Fieldwork Timetable: } 3 \text { days } \\
\text { @ 2hrs per day }\end{array}$ & $\begin{array}{c}\text { Participant } \\
\text { Observations }\end{array}$ & 2 & 4 & Field Notes \\
\hline
\end{tabular}

$\{P S\}$

Located at the rear of a very busy hospital on the outskirts of Edinburgh. Difficult to locate, is not signposted within the main hospital entrance. Looked like an industrial unit from the outside. Difficult to identify the main entrance as this was located to the very rear of the building. Natural instinct would expect to see it at the front of the building.

$\{A\}$

Several medium sized trucks were parked outside and large containers which looked like meals on wheels trolleys were being unloaded onto the courtyard.

This was a daily occurrence as the unit is opened $24 \mathrm{hrs}$ a day. This looked like a two man job, but was carried out by a single person. Once inside the unit, the trolley was identified and opened to identify the contents. No operational instructions were uttered, which gave the appearance of complete knowledge of the process.

The 2 staff who were in this area knew exactly what to do with the items inside and were clearly very confident in their approach to the nature of the contents. Since these were surgical instruments and items used to operate on people and were inevitably covered in blood and tissue. Their attitude to the contents was very matter of fact. The relationship between them was quite light almost light hearted

$\{$ II $\}$

One item slipped as it was being examined inside the trolley but did not seem to phase either person.

When unloading and scanning the items from the trolley, the conversation was of a social nature and there was no direct instructions passed between the participants of the unloading process.

The lack of communication regarding the actual work being undertaken seemed to be sparse, almost non existent. 


\begin{tabular}{r|cccc}
\multicolumn{2}{c}{ Observational Area 6 } & Method & Participants & \multicolumn{2}{c}{$\begin{array}{l}\text { Observatio } \\
\text { ns }\end{array}$} & Format \\
\hline 4 hours Fieldwork Timetable: 2 days & Participant & 3 & & Field Notes \\
@ 2hrs per day & & & & \\
KEY & & &
\end{tabular}

\section{$\{P S\}$}

Located at the rear of a very busy hospital on the outskirts of Edinburgh. Difficult to locate, is not signposted within the main hospital entrance. Looked like an industrial unit from the outside. Difficult to identify the main entrance as this was located to the very rear of the building. Natural instinct would expect to see it at the front of the building.

$\{A\}$

Several medium sized trucks were parked outside and large containers which looked like meals on wheels trolleys were being unloaded onto the courtyard.

This was a daily occurrence as the unit is opened $24 \mathrm{hrs}$ a day. This looked like a two man job, but was carried out by a single person. Once inside the unit, the trolley was identified and opened to identify the contents. No operational instructions were uttered, which gave the appearance of complete knowledge of the process.

The 2 staff who were in this area knew exactly what to do with the items inside and were clearly very confident in their approach to the nature of the contents. Since these were surgical instruments and items used to operate on people and were inevitably covered in blood and tissue. Their attitude to the contents was very matter of fact. The relationship between them was quite light almost light hearted

$\{$ II $\}$

One item slipped as it was being examined inside the trolley but did not seem to phase either person.

$\{N C\}$

When unloading and scanning the items from the trolley, the conversation was of a social nature and there was no direct instructions passed between the participants of the unloading process.

The lack of communication regarding the actual work being undertaken seemed to be sparse, almost non existent. 


\section{CONCLUSION}

This study focused on explaining the findings from both phases of the data collection in relation to the research within the HSDU department. Most feedback surrounded the interpolation of two perspective extremes of experience and capability, by delineating them between a coexistence of understanding and personal interpretation, a focused insight into elements of business success was achieved. The findings show that a personal perspective on knowledge is not restricted to cognitive capabilities nor organisation boundaries. The data explains that outwith this cognitive stance a conceptual understanding of knowledge contributes to the empathetic value given to knowledge transfer within this business context. In examining the findings from the data analysis was able to show that a personal view of knowledge contributes to the way in which it is used within a knowledge transfer arena. Additionally, whilst business success was enviable from both perspectives as a direct result of this knowledge transfer the underlying caveat for success was different between the two. The core of these findings is certainly more in line with assimilated knowledge, in the form of some sort of business framework or model which is derived from a holistic, harmonious, and well ordered. Good knowledge governance in this sense is therefore interpreted by this participant group as having the ability to bring development and prosperity to the business through justice and equitable rules. This interpretation of a business model is clearly not from a format or theory of contemporary business models but does represent an acknowledgement of alignment to a model of framework to justify success.

\section{BIBLIOGRAPHY}

1. Croll, P. 1(986) Systematic Classroom Observation, (see pages 84-93 on 'Observing in Classrooms').

2. Garfinkel, H., \& Sacks, H. (1986), 'On Formal Structures of Practical Actions', inGarfinkel, H. (ed.), Ethnomethodological Studies of Work, London, Routledge and Keegan Paul.

3. Glaser, B. and Strauss, A. (1967) The Discovery of Grounded Theory.

4. Goffman, E. (1968) Asylums: Essays on the Social Situation of Medical Patients and Other Inmates.

5. Patrick, J. (1975) A Glasgow Gang Observed.

6. Sacks, H. (1992), Lectures on conversation, Vol. 1, Oxford, Blackwell.

7. Strauss, A.; Schatzmann, L.; Bucher, R.; Ehrlich, D. and Sabshin, M. (1964) Psychiatric Ideologies and Institutions. 
6 APENDIX 1: OBSERVATION AND DIARY SHEET EXAMPLES 
TITLE: Daily Diary

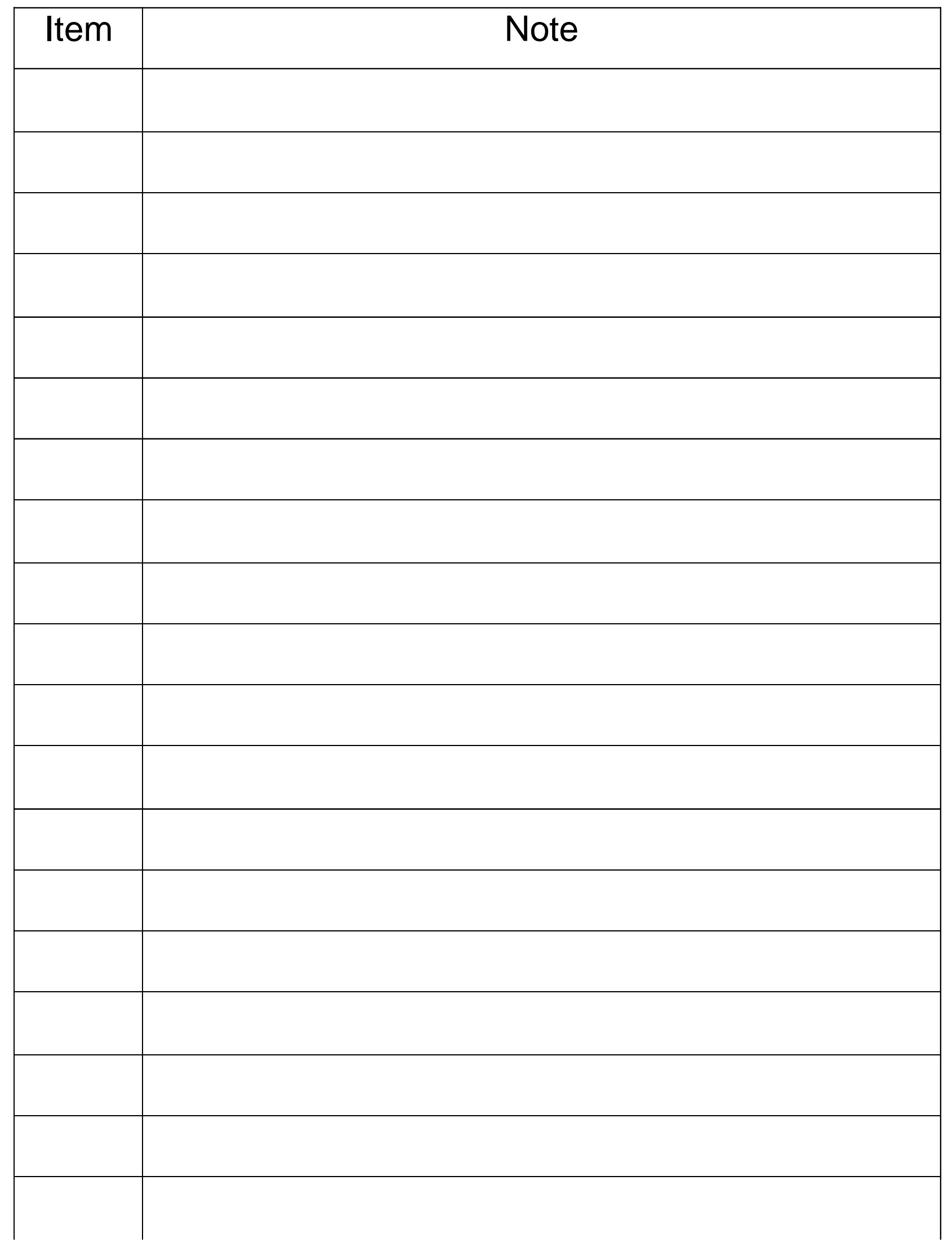


TITLE Observational Focus on Specific Task/Process

\begin{tabular}{|l|l|}
\hline ITEM & \\
\hline Introduction: & \\
\hline 1 point of view & \\
\hline 2 point of view & \\
\hline 3 point of view & \\
\hline 4 point of view & \\
\hline 5 point of view & \\
\hline 6 point of view & \\
\hline REMARKS & \\
\hline
\end{tabular}

List of key words and vocabulary

List of key observation 


\section{TITLE: Task Interaction}

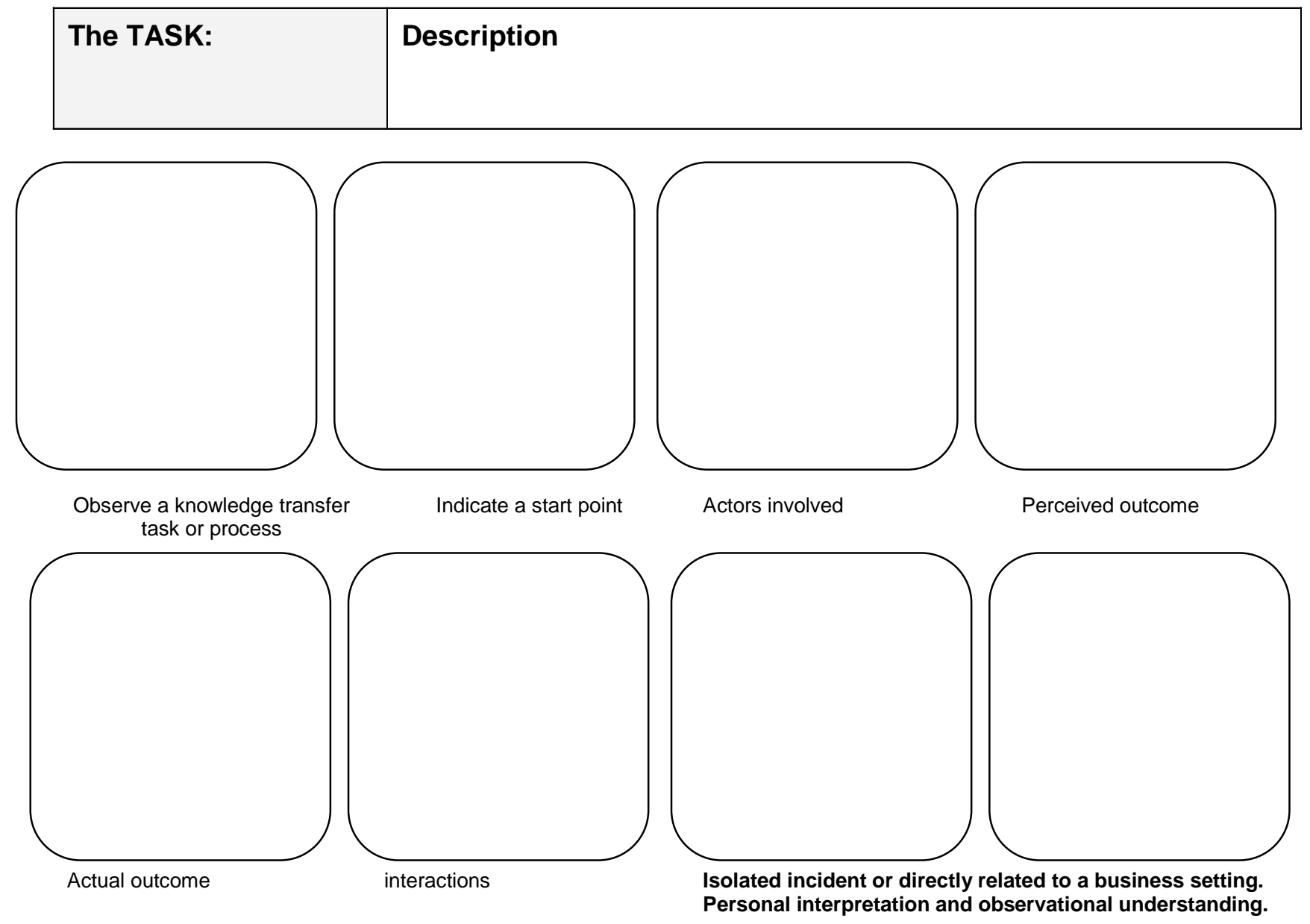

Observational Notes

List of key words and vocabulary

List of key observation 
